\title{
Neumonía por Corynebacterium pseudodiphteriticum: una patología a considerar
}

\author{
R. CARRANZA GONZÁLEZ, D. TENA GÓMEZ, E. PRIETO GÓMEZ, \\ J. R. BARBERÁ FARRÉ, J. FERNÁNDEZ CENJOR \\ Sección de Microbiología. Unidad de Neumología. Servicio de Medicina Interna. \\ Complejo Hospitalario La Mancha. Alcázar de San Juan. Ciudad Real
}

\section{RESUMEN}

Corynebacterium pseudodiphteriticum es considerado un patógeno respiratorio muy infrecuente. Presentamos 3 casos de neumonía atribuibles a C. pseudodiphteriticum, describiendo sus características clínicas y microbiológicas. En los dos primeros casos existía enfermedad respiratoria crónica previa, además de corticoterapia asociada en uno de ellos, y en el caso restante tan solo maniobras repetidas de intubación endotraqueal. El diagnóstico se orientó por la tinción de Gram, confirmándose con cultivos cuantitativos de muestras respiratorias. La evolución fue favorable en los 3 casos, tras tratamiento con amoxicilina-clavulánico, ceftriaxona y vancomicina respectivamente. C. pseudodiphteriticum debe ser tenido en cuenta como posible agente causal de neumonías, sobre todo en pacientes con patología respiratoria subyacente o sometidos a intubación endotraqueal. El tratamiento debe ajustarse al patrón de susceptibilidad a antimicrobianos, aunque los betalactámicos parecen ser la opción más adecuada.

PALABRAS CLAVE: Corynebacterium pseudodiphteriticum. Patógeno respiratorio. Neumonía. PNEUMONIA BY CORYNEBACTERIUM PSEUDODIPHTERITI-
CUM: AN INFECTION TO CONSIDER
ABSTRACT

Corynebacterium pseudodiphteriticum has been considered a very infrequent respiratory pathogen. We report three cases of pneumonia due to C. pseudodiphteriticum, describing their clinical and microbiological features. There were two patients with pre-existing chronic respiratory disease, one of their with steroidal therapy, and other associated with endotracheal intubation. The diagnostic was made by Gram stain and quantitative cultures from respiratory tract specimens. All patients were cured after treatment with amoxicillin-clavulanate, ceftriaxone and vancomycin respectively. C. pseudodiphteriticum must be consider as a possible causal agent of pneumonia in patients with underlying respiratory disease or endotracheal intubation. Antimicrobial susceptibility testing of C. pseudodiphteriticum may be useful for correct treatment of infected patients, but beta-lactam antibiotics are an appropriate therapeutic option against this bacteria.

KEY WORDS: Corynebacterium pseudodiphteriticum. Respiratory pathogen. Pneumonia.

Carranza González R, Tena Gómez D, Prieto Gómez E, Barberá Farré JR, Fernández Cenjor J. Neumonía por Corynebacterium pseudodiphteriticum: una patología a considerar. An Med Interna (Madrid) 2006; 124-126.

\section{INTRODUCCIÓN}

Corynebacterium pseudodiphteriticum es un bacilo gram positivo difterimorfo, considerado comensal que forma parte de la flora orofaríngea y cutánea. En los últimos años ha sido implicado fundamentalmente en infecciones respiratorias (13) (neumonía, traqueobronquitis) y de piel y tejidos blandos (malacoplaquia, linfadenitis supurada), pero también en endo- carditis, infecciones urinarias y protésicas (4). La mayoría de casos descritos afectaban a individuos inmunodeprimidos $(1,5,6)$ (VIH, lupus eritematoso, terapia corticoidea) aunque también se han documentado infecciones respiratorias en inmunocompetentes $(1,2,7$.) A continuación presentamos 3 casos de neumonías causadas por $C$. pseudodiphteriticum acontecidas en nuestro hospital, con el objetivo de conocer sus características epidemiológicas y clínicas.

Trabajo aceptado: 10 de octubre de 2005

Correspondencia: Rafael Carranza. Sección de Microbiología. Hospital General La Mancha Centro. 13600 Alcázar de San Juan. Ciudad Real. e-mail: rcarranza@sescam.jccm.es 


\section{CASOS APORTADOS}

Caso 1. Varón de 76 años de edad, fumador durante 60 años hasta hace 2 que cesó en este hábito, con antecedentes de EPOC sin tratamiento de forma habitual. Acude al servicio de urgencias por un cuadro de 48 horas de evolución de malestar general, dolor pleurítico en el lado izquierdo y aumento de la tos y expectoración habituales. En la exploración se apreciaron una temperatura corporal de $38{ }^{\circ} \mathrm{C}$ y una disminución difusa del murmullo vesicular con crepitantes y sibilancias en la base pulmonar izda. En la analítica general al ingreso destacaron 18.600 leucocitos $/ \mathrm{mm}^{3}, 92 \%$ neutrófilos, y una gasometría con $\mathrm{pCO}_{2}$ de $27 \mathrm{~mm} \mathrm{Hg}$, pO2 56,8, pH 7,48 y $\mathrm{HCO}_{3} 23,6$ con una saturación de $\mathrm{O}_{2}$ del $92 \%$. La radiografía torácica mostró un infiltrado alveolar en LII, LSI y língula y cardiomegalia. Se procedió al ingreso del paciente iniciando oxigenoterapia, administración de broncodilatadores inhalados, heparina de bajo peso molecular a dosis profiláctica y tratamiento antimicrobiano con levofloxacino intravenoso (500 mg/24 horas). El cuadro evolucionó lentamente, manteniéndose la febrícula y la insuficiencia respiratoria y las muestras de esputo para tinción de Gram y cultivo no fueron valorables, resultando los hemocultivos negativos. Por todo ello, 6 días después del ingreso se decide realizar una fibrobroncoscopia. En la muestra del aspirado bronquial se observaron en la tinción de Gram abundantes polimorfonucleares (> $25 \mathrm{PMN} / \mathrm{c}$ x 100) y bacilos gram positivos difterimorfos extra e intracelulares, creciendo posteriormente en cultivo puro C. pseudodiphteriticum resistente a clindamicina, eritromicina y ciprofloxacina y sensible a penilina, amoxicilina-clavulánico, cefalosporinas de $2^{\mathrm{a}}$ y $3^{\mathrm{a}}$ generación y glicopéptidos. El informe anatomopatológico confirmó el frotis del exudado bronquial como proceso inflamatorio agudo sin evidencia de otras lesiones. Con el diagnóstico de neumonía por $C$. pseudodiphteriticum se cambió el tratamiento a amoxicilina-clavulánico $2 \mathrm{~g} / 8 \mathrm{~h}$ i.v., evolucionando el paciente de forma favorable.

Caso 2. Hombre de 65 años, exfumador importante hasta hace 6 años, diagnosticado de síndrome de Sjögren hace 6 meses y controlado desde entonces con corticoides orales (90 mg de prednisona/ día). El día del ingreso presentó disnea súbita y progresiva junto a dolor torácico de carácter pleurítico. Además en la anamnesis refirió odinofagia y disfagia intermitentes de 3 meses de evolución. En la exploración en urgencias se observó una temperatura de $38{ }^{\circ} \mathrm{C}$ con una disminución global del murmullo vesicular y crepitantes inspiratorios en ambas bases pulmonares. En la analítica inicial destacaron 8.200 leucocitos $/ \mathrm{mm}^{3}$ ( $85 \%$ neutrófilos), PCR de $6,7 \mathrm{mg} / \mathrm{dl}$ y en la gasometría $\mathrm{pO}_{2}$ de 51,8 mm Hg, $\mathrm{pCO}_{2} 29,7, \mathrm{pH} 7,54, \mathrm{HCO}_{3} 25$ con saturación de $\mathrm{O}_{2} 91 \%$. La radiografía de tórax indicaba un aumento de densidad en LID y cardiomegalia. El paciente ingresa en el hospital con oxigenoterapia continua, broncodilatadores, corticoides, heparina de bajo peso molecular a dosis terapéuticas por sospecha de tromboembolismo pulmonar, aciclovir y antibioterapia de amplio espectro (ceftriaxona $1 \mathrm{~g} / 24$ horas). Las muestras de esputo no fue- ron aptas para cultivo, resultando los hemocultivos estériles a los 5 días. A las 48 horas del ingreso se realizó una fibrobroncoscopia con lavado broncoalveolar, en el que se observaron en la tinción de Gram numerosos leucocitos polimorfonucleares y bacilos gram positivos difterimorfos intra y extracelulares, cultivándose $C$. pseudodiphteriticum (> $100.000 \mathrm{UFC} / \mathrm{ml}$.). La cepa fue resistente a clindamicina y eritromicina y sensible a penilina, amoxicilina-clavulánico, cefalosporinas de $2^{\mathrm{a}}$ y $3^{\mathrm{a}}$ generación, ciprofloxacino y glicopéptidos. Así mismo se hicieron una TC torácica, apreciándose un mediastino normal con patrón alveolar de contornos poco definidos en LID, y gastroscopia en la que destacan varias úlceras desde el tercio medio esofágico al cardias, compatibles con úlceras por virus del grupo herpes. La gammagrafía pulmonar de ventilación-perfusión no mostró hallazgos relevantes. La evolución resultó satisfactoria, desapareciendo la sintomatología y mejorando los parámetros gasométricos y bioquímicos con resolución del infiltrado.

Caso 3. Mujer de 68 años, diabética insulín-dependiente, obesa y alérgica a penicilina, que acude al hospital tras un accidente de tráfico que le ocasiona traumatismos torácico y craneoencefálico leves, fractura de fémur drcho., que requirió estabilización mediante osteosíntesis, y fractura conminuta de húmero izdo., inmovilizada con férula. Después de la inducción para la intervención traumatológica se apreció edema supraglótico y bradicardia que requirió la administración de atropina. La paciente pasó a UCI dadas las características de su vía aérea, ingresando en coma bajo efectos farmacoanestésicos, hemodinámicamente estable, con acidosis metabólica parcialmente compensada, leucocitosis y anemia. Se inició tratamiento con hemoderivados y soluciones hidroelectrolíticas, administrándose corticoides con vistas a extubación 24-48 horas después. A las 24 h se realizó una prueba de desconexión de la ventilación mecánica, pero la aparición de un cuadro de distress respiratorio del adulto con empeoramiento del intercambio gaseoso obligó a reintubar a la paciente. En días posteriores se reintentó la extubación en dos ocasiones sin éxito, por presentación de edema supraglótico e insuficiencia respiratoria. En un control de aspirado traqueal remitido al laboratorio de microbiología a las $48 \mathrm{~h}$. del ingreso en UCI se aisló Haemophilus influenzae (10.000 UFC/ml), observándose en la tinción de Gram 5-10 leucocitos PMN/c x 100 y moderadas células epiteliales. Pese a no cumplir criterios claros de neumonía asociada a ventilación mecánica, se pautó tratamiento con levofloxacino durante 6 días $(500 \mathrm{mg} /$ 24 h i.v.). En este intervalo de tiempo se procedió a los intentos de extubación citados, apareciendo fiebre y leucocitosis con progreso de los infiltrados pulmonares en la radiografía de tórax, por lo que se envió un nuevo aspirado traqueal para cultivo. En él se vieron abundantes PMNs ( $>25 / \mathrm{c}$ x 100) con bacilos gram positivos difterimorfos extra e intracelulares, creciendo $100.000 \mathrm{UFC} / \mathrm{ml}$. de C. pseudodiphteriticum resistente a clindamicina, eritromicina y ciprofloxacina y sensible a penilina, amoxicilina-clavulánico, cefalosporinas de $2^{\mathrm{a}} \mathrm{y}$ $3^{\text {a }}$ generación y glicopéptidos. Con este resultado, se administró vancomicina $500 \mathrm{mg} / 12$ h. i.v. durante 7 días más, evolucionado la

\begin{tabular}{lllllll} 
& Edady Sexo & $\begin{array}{c}\text { TABLA I } \\
\text { Enfermedad } \\
\text { de base }\end{array}$ & $\begin{array}{l}\text { Factores } \\
\text { predisponentes }\end{array}$ & Muestra & Tratamiento & Evolución \\
\hline Caso1 & $\begin{array}{l}\text { Hombre, } \\
76 \text { años }\end{array}$ & EPOC & EPOC, & $\begin{array}{l}\text { Aspirado } \\
\text { bronquial }\end{array}$ & $\begin{array}{l}\text { Levofloxacina/ } \\
\text { Amoxicilina- } \\
\text { clavulánico }\end{array}$ & Curación \\
\hline Caso 2 & $\begin{array}{l}\text { Hombre, } \\
65 \text { años }\end{array}$ & $\begin{array}{l}\text { EPOC, } \\
\text { S. Sjögren }\end{array}$ & $\begin{array}{l}\text { Corticoterapia, } \\
\text { EPOC }\end{array}$ & $\begin{array}{l}\text { Lavado } \\
\text { bronquial }\end{array}$ & Ceftriaxona & Curación \\
\hline Caso 3 & $\begin{array}{l}\text { Mujer, } \\
68 \text { años }\end{array}$ & $\begin{array}{l}\text { DMID, } \\
\text { Politrauma }\end{array}$ & $\begin{array}{l}\text { Intubación } \\
\text { repetida }\end{array}$ & $\begin{array}{l}\text { Aspirado } \\
\text { traqueal }\end{array}$ & $\begin{array}{l}\text { Levofloxacina/ } \\
\text { Vancomicina }\end{array}$ & Curación \\
\hline
\end{tabular}

DMID: diabetes mellitus insulín-dependiente, 
paciente satisfactoriamente y consiguiendo finalmente ser extubada y pasar a planta de hospitalización para continuar el tratamiento ortopédico.

Las principales características de los tres casos se resumen en la tabla I.

\section{IDENTIFICACIÓN Y SUSCEPTIBILIDAD A ANTIMICROBIANOS}

Las características bioquímicas de las 3 cepas fueron determinadas mediante el sistema comercial API Coryne (bioMèrieux, Francia). Las pruebas de susceptibilidad a los antimicrobianos se realizaron utilizando el método de difusión en disco de Kirby-Bauer sobre agar Mueller-Hinton suplementado con 5\% de sangre lisada de caballo siguiendo las recomendaciones del NCCLS 8.

\section{DISCUSIÓN}

Desde el primer caso de neumonía por C. pseudodiphteriticum comunicado en 19836 hasta las cortas series publicadas en 1995 1,2 y las últimas revisiones sobre su papel en las neumonías comunitarias 9, esta bacteria ha sido relacionada con infecciones respiratorias en individuos inmunocomprometidos o con el sistema inmunitario indemne y a menudo con factores predisponentes o enfermedades respiratorias subyacentes. Los presentes casos aportados confirman el papel etiopatogénico de $C$. pseudodiphteriticum en neumonías. En cuanto a los factores predisponentes existía EPOC en los casos 1 y 2, coincidiendo además la terapia con corticoides por síndrome de Sjögren en uno de ellos (caso 2) y repetidas maniobras de intubación endotraqueal en el caso 3. En este último no había antecedente de enfermedad respiratoria previa ni inmunodepresión evidente, aunque se produjo un cambio en la flora $H$. influenzae) y 6 días más tarde (C. pseudodiphteriticum), que coincidió con las sucesivas maniobras de intubación y extubación realizadas. Estimamos que los tres casos descritos cumplen los criterios microbiológicos necesarios para considerar a $C$. pseudodiphteriticum el agente etiológico de la infección neumónica: intensa respuesta inflamatoria por leucocitos polimorfonucleares en las muestras respiratorias, con abundantes bacilos gram positivos difterimorfos intra y extraleucocitarios, junto al aislamiento en cultivo puro y en recuentos altos $(105 \mathrm{UFC} / \mathrm{ml})$ de la citada bacteria. Las cepas cultivadas tuvieron un patrón de susceptibilidad a antimicrobianos común, con resistencia in vitro a macrólidos y lincosamidas y, en dos ocasiones, también a ciprofloxacina, siendo sensibles a penicilina, cefalosporinas y glicopéptidos. Posiblemente en los casos 1 y 3 , el tratamiento con levofloxacino favoreció la selección en el árbol bronquial de C. pseudodiphteriticum resistente a quinolonas. En los tres casos comunicados la respuesta terapéutica fue buena tras ajustar el tratamiento al antibiograma, empleando betalactámicos en los casos 1 y 2 y vancomicina en el tercero.

En conclusión, debe considerarse la posibilidad de infección respiratoria por $C$. pseudodiphteriticum especialmente en aquellos pacientes que presenten enfermedad respiratoria crónica, algún tipo de compromiso inmunitario o hayan sido sometidos a intubación endotraqueal repetida. La tinción de Gram de las muestras respiratorias orientará inicialmente la sospecha diagnóstica y el tratamiento, confirmándose con los cultivos cuantitativos y el estudio de susceptibilidad a antimicrobianos del aislado. De cualquier forma, dado el perfil de sensibilidad tan constante que ofrece $C$. pseudodiphteriticum, los betalactámicos como cefalosporinas de $3^{\mathrm{a}}$ generación y amoxicilina-clavulánico parecen ser el grupo terapéutico más adecuado para tratar las infecciones producidas por esta bacteria.

\section{Bibliografía}

1. Ahmed K, Kawakami K, Watanabe K, Mitsushima H, Nagatake T, Matsumoto K. Corynebacterium pseudodiphteriticum: a respiratory tract pathogen. Clin Infect Dis 1995; 20: 41-6.

2. Manzella JP, Kellog JA, Parsey KS. Corynebacterium pseudodiphteriticum: a respiratory tract pathogen in adults. Clin Infect Dis 1995; 20: 37 40.

3. Reynolds HY. Respiratory infections: commmunity- acquired pneumonia and newer microbes. Lung 1996; 174: 207-24.

4. Brown AE. Other Corynebacteria and Rhodococcus. In: Mandell GL, Bennett JE, Dolin R, eds. Principles and Practice of Infectious Diseases. 5th ed. New York: Churchill Livingstone; 2000: p. 21982204.

5. Gutiérrez-Rodero F, Ortiz de la Tabla V, Martínez C, Masiá MM, Mora A, Escolano C, et al. Corynebacterium pseudodiphteriticum: an easily missed respiratory pathogen in HIV-infected patients. Diagn Microbiol
Infect Dis 1999; 33: 209-16.

6. Donaghy M, Cohen J. Pulmonary infection with Corynebacterium hofmannii complicating systemic lupus erithematosus. J Infect Dis 1983; 147: 962.

7. Chiner E, Arriero JM, Signes-Costa J, Marco J, Corral J, Gómez-Espárrago $\mathrm{A}$, et al. Corynebacterium pseudodiphteriticum pneumonia in an immunocompetent patient. Monaldi Arch Chest Dis 1999; 54: 325-7.

8. National Committee for Clinical Laboratories Standards. Performance standards for antimicrobial disk susceptibility tests; Approved standard. Seventh edition. NCCLS document M2-A7. 2000

9. Chudnicka A, Szmygin-Milanowska K, Kieszko R, Milanowski J, Koziol-Montewka M. The role of opportunistic species of Corynebacterium pseudodiphteriticum in the pathogenesis of CAP (Community Acquired Pneumonia). Ann Univ Mariae Curie Sklodowska (Med) 2003; 58: 142-8. 